\title{
Birth defects following maternal exposure to ergotamine, beta blockers, and caffeine
}

\author{
HELEN E HUGHES* AND DANIEL A GOLDSTEIN $\dagger$ \\ From * the Institute of Medical Genetics, University Hospital of Wales, Cardiff; and the Division of Clinical \\ Pharmacology, The Hospital for Sick Children, Toronto, Canada.
}

SUMMARY Ergotamine exposure during pregnancy has been suggested to cause birth defects which have a vascular disruptive aetiology. The present case provides additional support for the possible adverse fetal effects of exposure to ergotamine, caffeine, and propranolol during the first four months of pregnancy. At birth the infant showed evidence of early arrested cerebral maturation and paraplegia. The nature of these defects suggests a primary vascular disruptive aetiology. We hypothesise that ergotamine, acting either alone or in synergy with propranolol and caffeine, produced fetal vasoconstriction resulting in tissue ischaemia and subsequent malformation. This case raises the possibility that fetal malformation may result from concomitant use of multiple vasoconstrictive agents during pregnancy.

It is now accepted that a variety of anomalies such as limb reduction defects, porencephalic cysts, microcephaly, intestinal atresia, and paraplegia can result from vascular disruptive phenomena in utero. ${ }^{1}$ The types of congenital defects depend on the fetal vessels involved and the duration, timing, and mechanism of injury. ${ }^{2}$ Vascular injury with subsequent tissue anoxia can result from a number of mechanisms such as thromboembolic phenomena in a monozygotic twin survivor after death of a co-twin in utero, maternal hypotension/hypertension, uterine artery occlusion, and vasculitis. ${ }^{1-4}$

Vasoconstrictive agents also have been implicated as causes of birth defects with a vascular disruptive aetiology. For example, ergotamine has been suggested as a possible cause of intestinal atresia. Indirectly, ergotamine has been implicated as one cause of Poland sequence following its use as an abortifacient. ${ }^{6}$ The present case report provides further support for the hypothesis that birth defects may result from vascular occlusion caused by ergotamine therapy during pregnancy. The potentiating effect of-concomitant exposure to multiple vasoconstrictive agents is suggested.

\section{Case report}

The infant, a Caucasian female (fig 1), was born at

Received for publication 2 June 1987.

Revised version accepted for publication 23 June 1987 term after spontaneous onset of labour. She was the product of the first pregnancy of a young, nonconsanguineous couple with an unremarkable family history. However, the mother had been treated for

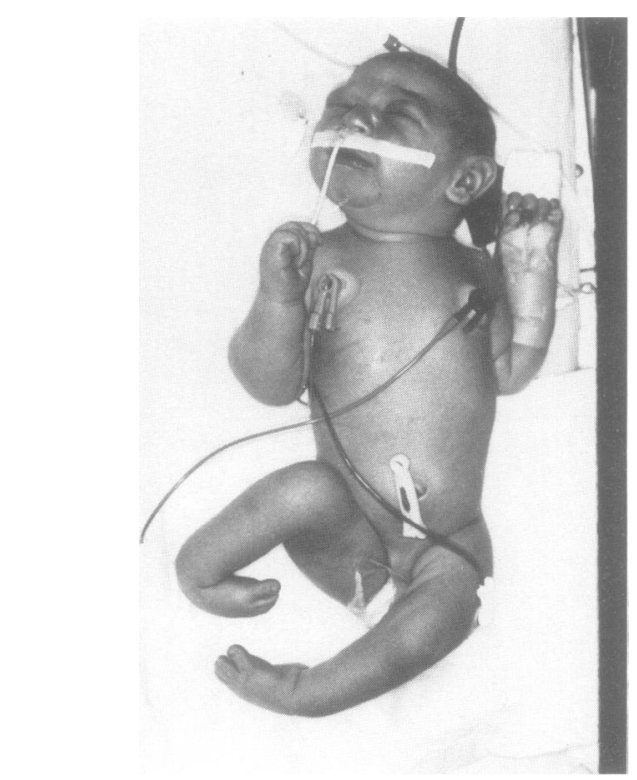

FIG 1 Infant in newborn period. Note microcephaly and underdeveloped, contracted lower limbs. 
migraine and pregnancy was complicated by severe migraine headaches which were treated with a variety of medications including ergotamine and caffeine, taken in the form of 'cafergot' suppositories, and propranolol (table). There was no history of smoking, alcohol or other drug intake, decreased fetal movements, vaginal bleeding, toxaemia, or hypotension.

The infant was a breech presentation. Birth weight was $2860 \mathrm{~g}$ and length was approximately 46 $\mathrm{cm}$ (compromised by lower limb contractures). She was clinically microcephalic with a head circumference of $31 \mathrm{~cm}$ and the anterior fontanelle was almost closed. There were no facial dysmorphic features and the baby's upper trunk and arms were normally developed. The movements and tone were normal in the upper limbs and the reflexes were brisk.

TABLE Medications taken during pregnancy.

\begin{tabular}{|c|c|c|c|}
\hline & & Dose & $\begin{array}{l}\text { Gestation } \\
\text { (wk) }\end{array}$ \\
\hline $\begin{array}{l}\text { Acetaminophen } \\
\text { Codcine }\end{array}$ & $\begin{array}{rl}325 & \mathrm{mg} \\
8 \mathrm{mg}\end{array}$ & $6-20 / \mathrm{d} a y$ & $11-16$ \\
\hline Propranolol & 4) $\mathrm{mg}$ & 2/day & $0-20$ \\
\hline $\begin{array}{l}\text { Ergotamine } \\
\text { Caffeine } \\
\text { L Belladona alk } \\
\text { Pentobarbital }\end{array}$ & $\begin{array}{r}2 \mathrm{mg} \\
100 \mathrm{mg} \\
(1.25 \mathrm{mg} \\
61) \mathrm{mg}\end{array}$ & 1-4/week & $0-14$ \\
\hline Dimenhydrinate & $75 \mathrm{mg}$ & $11-3 /$ weck & $11-12$ \\
\hline
\end{tabular}

The information in this table was provided retrospectively by the mother. She appeared to be an accurate historian and was sure of the date of conception. Both 'afergot' and propranolol were prescribed by her physician.
However, the infant was paraplegic with underdeveloped and hypotonic lower limbs. The anal, knee, and ankle reflexes were absent. Sensation was absent up to the level of the knees and it was variably absent on the thighs. The findings suggested a spinal cord abnormality and it was estimated to be in the upper lumbar region. Both hips were dislocated and there was a marked equinovarus deformity bilaterally.

INVESTIGATIONS

Radiographs of the lower limbs revealed osteoporosis and fractures of the femora and tibiae. In contrast, the bone density in the arms was normal. The spine was also normal with no evidence of dysraphism. An electromyographic study was normal in the biceps, but in the lower limbs sensory action potentials were absent and only very minimal motor action potentials were recorded. The findings were consistent with a spinal cord lesion or myelodysplasia. However, a CT scan of the cord failed to reveal a structural abnormality. A CT scan of the head showed a small brain with lissencephaly, a primitive Sylvian fissure, and ventriculomegaly. The corpus callosum and falx were present (fig $2 \mathrm{a}$, b).

The infant's lymphocyte chromosomes were normal (46, XX, Giemsa banded) and antibody titres (toxoplasma, rubella, cytomegalovirus, and herpes simplex) in both mother and baby were not raised. Urine and cerebrospinal fluid viral cultures were also negative. The placenta and membranes were examined in detail and were unremarkable with no

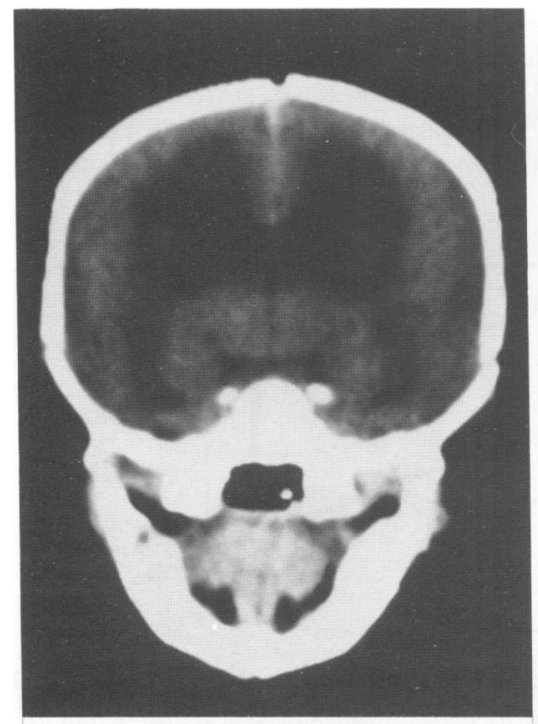

(a)

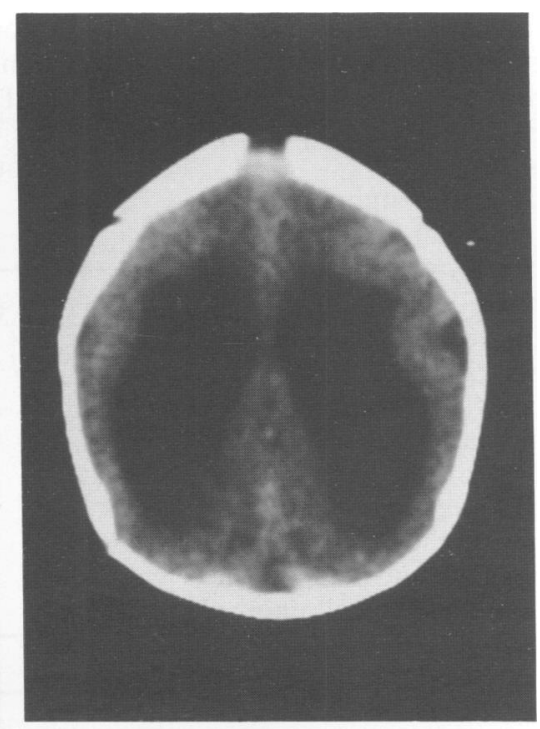

(b)
FIG 2 CT scans in newborn period. Coronal section (a) shows presence of falx and 'bat-wing' dilatation of lateral ventricles, a sign commonly associated with early arrest of cerebral development. Note in section (b) lack of sulci and gyri except for a shallow Sylvian fissure. 
evidence of a twin pregnancy and no areas of infarction. The cord was $42 \mathrm{~cm}$ in length and had three vessels which were patent at all levels sectioned.

\section{Discussion}

The co-occurrence of the brain abnormality and cord lesion in this infant could be accounted for by a vascular disruptive mechanism, such as in utero hypoperfusion of the fetal cerebral and spinal vessels. ${ }^{7}$ The brain CT scan findings are compatible with the arrest of cerebral development early in the second trimester of pregnancy. Presence of the corpus callosum and falx suggest that the insult occurred later than 10 to 13 weeks of gestation. ${ }^{89}$ The infant's spinal cord lesion could have occurred either as a result of an acute disruption of blood supply or from chronic hypoperfusion with consequent ischaemia in one of the spinal cord watershed areas. These watershed regions are most vulnerable to vascular deprivation because they are the most distal regions perfused by a given arterial supply. ${ }^{10}$ One such area, L1, is compatible with the neurological findings in this infant.

It is significant that the infant in this report was exposed to ergotamine, caffeine, and propranolol during the first 14 to 20 weeks of gestation. Propranolol and caffeine are known to cross the placental barrier and will produce pharmacological effects in the fetus. ${ }^{11}$ Ergotamine has also been shown to cross the placenta in small quantities. ${ }^{12}$ No other predisposing cause for the birth defects could be indentified. Specifically, there was no history of either acute or chronic maternal hypotension and, to the best of our knowledge, the other drugs ingested (table) have not been associated with birth defects comparable to those in this infant. ${ }^{13}$

The ergot alkaloids, including ergotamine, have a wide range of effects upon vascular regulation at levels ranging from the central nervous system to the vessel wall. ${ }^{14}$ These agents have documented pharmacological effects on multiple receptors including alpha adrenergic, cholinergic, and -serotoninergic sites. Ergotamine has been used for some time in the therapy of migraine although the precise mechanisms by which ergotamine results in overall pressor effects have not been defined. Nevertheless, physiological studies have consistently shown a specific pattern of vascular responsiveness and the potent vasoconstrictive power of ergotamine is well known from the gangrene and multiple organ infarction seen with therapeutic and accidental ergotism. ${ }^{15}$ Therapeutic benefit can be derived from the drug at doses which do not induce diffuse vasospasm, suggesting that there is some specificity of action on cerebral vasculature. ${ }^{16}$

Caffeine also presents a complex pharmacological picture. In general, caffeine is a smooth muscle relaxant and vasodilator. However, it appears to exert a constrictor effect on human cerebral vasculature. ${ }^{17-19}$ Thus, it is reasonable to speculate that the synergistic effect of caffeine and ergotamine could result in a more pronounced vasoconstriction of the cerebral vessels. This effect is shown in dogs where dihydroergotamine alone does not cause cerebral vasoconstriction but is a potent vasoconstrictor in the presence of caffeine ${ }^{20}$ It is possible that caffeine may enhance the apparent specificity for cerebral vessels by acting as a vasodilator in other vascular beds.

Propranolol, the prototypical beta adrenergic blocker, acts as a vasoconstrictor in most or all vascular beds by interfering with the vasodilating effects of peripheral beta receptors. This effect is usually masked by decreased cardiac contractility which results in a net fall in blood pressure. Poor peripheral circulation is often noted as a side effect of propranolol therapy and on rare occasions beta blockade has resulted in peripheral ischaemia with gangrene. ${ }^{21}$ In the presence of beta blockade, the unbalanced alpha-like activity of ergotamine might be expected to result in more severe vasoconstriction. For example, two patients who received a combination of a beta blocker and ergotamine developed severe peripheral ischaemia. ${ }^{22}$ It would appear that the concomitant use of ergotamine, caffeine, and propranolol might increase the risk for severe vasoconstrictive complications (fig 3 ).

Case reports provide the initial suggestion that a specific agent may be teratogenic and may stimulate initiation of small prospective series of exposed pregnancies. ${ }^{23}$ Obviously, the true teratogenic risk of the various vasoconstrictive agents can only be

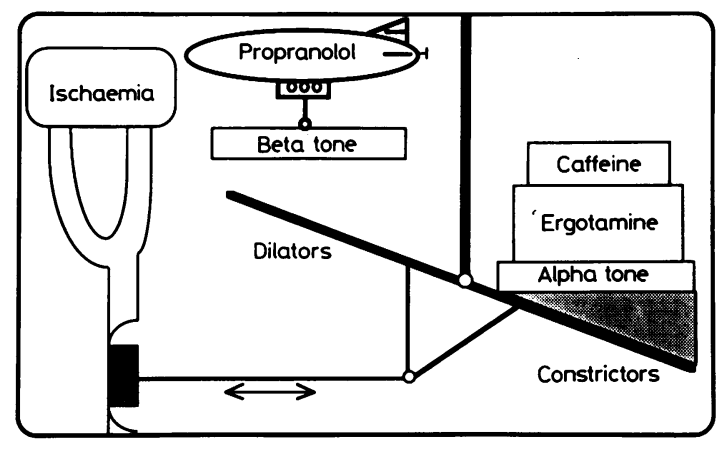

FIG 3 Schema to demonstrate the synergistic action of caffeine, ergotamine, and propranolol on vascular tone. 
estimated by population studies, but such data would be difficult to obtain because of the known oxytocic effect of ergot derivatives. To date, studies on offspring of women treated for migraine have not shown an increased risk of congenital malformations. ${ }^{2425}$ However, the number of subjects in these studies is small so that the effect of a weak or inconsistent teratogen, or the result of multiple drug interaction, could be missed. The Collaborative Perinatal Project ${ }^{24}$ reported on 25 exposures to ergotamine and 32 exposures to other ergot derivatives. The relative risk of malformation was 1.24 and 1.45 respectively. A retrospective study of the association between maternal migraine and malformations in offspring ${ }^{25}$ showed that $70 \%$ of women had taken ergot alkaloids at some time in the past, but no data regarding exposure during pregnancy were obtained. Thus, the actual number of exposed women and severity of exposure are unknown.

The present case suggests the need for caution in the use of combined vasoconstrictive agents for the treatment of migraine during pregnancy. Therapy with ergotamine combined with caffeine or beta blocking agents or both may place the fetus at increased risk for malformations with a vasoocclusive aetiology.

The authors would like to thank Drs J K Finegan and S Spielberg for their comments on the manuscript.

\section{References}

${ }^{1}$ Hoyme HE, Higginbottom MC, Jones KL. Vascular etiology of disruptive structural defects in monozygotic twins. Pediatrics 1981;67:288-91.

2 van Allen MI. Fetal vascular disruptions: mechanisms and some resulting birth defects. Pediatr Ann 1981;10:31-50.

${ }^{3}$ Benirschke $\mathrm{K}$. Twin placenta in perinatal mortality. NY State $\mathrm{J}$ Med 1961;61:1499-508.

4 Schinzel AAGL, Smith DW, Miller JR. Monozygotic twinning and structural defects. J Pediatr 1979;95:921-30.

5 Graham JM, Marin-Padilla M, Hoefnagel D. Jejunal atresia associated with cafergot ingestion during pregnancy. Clin Pediatr 1983;22:226-8.

6 David TJ. Nature and etiology of the Poland anomaly. $N$ Engl $J$ Med 1972;287:487-9.

${ }^{7}$ Myers RE. Brain damage induced by umbilical cord compression at different gestational ages in monkeys. In: Goldsmith EI, Moor-Jankowski J, eds. Medical primatology. Proc 2nd Conf Exp Med Surg Primates. Basel: Karger, 1970:394-425.
${ }^{8}$ Hamilton WJ, Mossman HW. Human embryology. Cambridge: W Heffer, 1972:475.485.

${ }^{9}$ Rakic P. Yakovlev PI. Development of the corpus callosum in man. J Comp Neurol 1968:132:45-72.

10 Moore KL. Clinically orientated anatomy. Baltimore: Williams and Wilkins, 1980:651-5.

1 Briggs GG, Bodendorfer TW. Freeman RH, et al. Drugs in pregnancy and lactation. Baltimore: Williams and Wilkins, 1981:312.

12 Griffith RW, Grauwiler J, Holdel $\mathrm{CH}$, et al. Toxicologic considerations. In: Berde B, Schild HO, eds. Ergot alkaloids and related compounds. Handbook of experimental pharmacology. Vol 49. Berlin: Springer Verlag. 1979:805-51.

13 Briggs GG, Bodendorfer TW, Freeman RH, et al. Drugs in pregnancy and lactation. Baltimore: Williams and Wilkins, 1981:310.

${ }^{14}$ Clark BJ, Chu D, Aellig WH. Actions on the heart and circulation. In: Berde B, Schild HO, eds. Ergot alkaloids and related compounds. Handbook of experimental pharmacology. Vol 49. Berlin: Springer Verlag, 1979:322-420.

15 Dukes MNG. Drugs affecting the autonomic system. In: Dukes MNG. ed. Mylers side effects of drugs. 10th ed. Amsterdam: Excerpta Medica, 1984:224-46.

16 Saxena PR, de Vlaam-Schluter GM. Role of some biogenic substances in migrainc and relevant mechanism in the antimigrainc action of ergotamine. Headache 1974;13:142-62.

17 Wechsler RL, Lee MK, Kety SS. The effects of intravenously administered aminophylline on cerebral circulation and metabolism in man. J Clin Invest 1950;29:28-30.

${ }^{18}$ Moyer JH, Tashnek AB, Miller SI, et al. The effect of theophylline with ethylenediamine, aminophylline and caffeine on cerebral hemodynamics and cerebrospinal fluid pressure in patients with hypertensive headaches. Am J Med Sci 1952;224:377-85.

${ }^{19}$ Skinhoj E, Paulson OB. The mechanism of action of aminophylline upon cercbrovascular disorders. Acta Neurol Scand 1970;56:129-40.

20) van den Bergh R. L influence de quelques medicaments usuels sur la vasomotricity carotidienne. Acta Neurol Belg 1956;56:459-75.

21 Vale JA. Jefferys DB. Peripheral gangrene complicating beta blockade. Lancet 1978;i:1216.

22 Venter CP, Joubert PH. Buys AC. Severe peripheral ischacmia during concomitant use of beta blockers and ergot alkaloids. $\mathrm{Br}$ Med J 1984;289:288-9.

${ }^{23}$ Goldberg JD, Golbus MS. The value of case reports in human teratology. Am J Obstet Gynecol 1986:154:479-82.

${ }^{24}$ Heinonen OP. Slone D. Shapiro S. Birth defects and drugs in pregnancy. Littleton, MA: Publishing Sciences Group, 1977:358.

25 Wainscott G, Sullivant FM, Volans GN, et al. The outcome of pregnancy in women suffering from migraine. Postgrad Med $J$ 1978:54:98-102.

Correspondence and requests for reprints to Dr $\mathrm{H}$ E Hughes, Institute of Medical Genetics, University Hospital of Wales, Heath Park, Cardiff CF4 4XN. 